\title{
Study and Control of a Radial Vaned Diffuser Stall
}

\author{
Aurélien Marsan, ${ }^{1}$ Isabelle Trébinjac, ${ }^{2}$ Sylvain Coste, ${ }^{1}$ and Gilles Leroy ${ }^{1}$ \\ ${ }^{1}$ Turbomeca, Safran Group, BP 17, 64511 Bordes Cedex, France \\ ${ }^{2}$ LMFA, UMR 5509, Ecole Centrale de Lyon, UCB Lyon I and INSA, 69134 Ecully Cedex, France
}

Correspondence should be addressed to Aurélien Marsan, aurelien.marsan@ec-lyon.fr

Received 20 July 2012; Accepted 29 October 2012

Academic Editor: Seyed G. Saddoughi

Copyright (C) 2012 Aurélien Marsan et al. This is an open access article distributed under the Creative Commons Attribution License, which permits unrestricted use, distribution, and reproduction in any medium, provided the original work is properly cited.

The aim of the present study is to evaluate the efficiency of a boundary layer suction technique in case of a centrifugal compressor stage in order to extend its stable operating range. First, an analysis of the flow pattern within the radial vaned diffuser is presented. It highlights the stall of the diffuser vanes when reaching a low massflow. A boundary layer separation in the hub-suction side corner grows when decreasing the massflow from the nominal operating point to the surge and finally leads to a massive stall. An aspiration strategy is investigated in order to control the stall. The suction slot is put in the vicinity of the saddle that originates the main separating skin-friction line, identified thanks to the analysis of the skin-friction pattern. Several aspiration massflow rates are tested, and two different modelings of the aspiration are evaluated. Finally, an efficient control is reached with a removal of only $0,1 \%$ of the global massflow and leads-from a steady-state calculations point of view-to an increase by $40 \%$ of the compressor operating range extent.

\section{Introduction}

The stable operation of compressors is limited towards low massflow by the occurrence of flow instabilities. To prevent the release of these instabilities, that can be destructive, compressors never operate closer to the stability limit than a chosen massflow. That is called the "surge-margin." Essential for the stability of the compressor working, it is however in this forbidden part of the operating map that the compressor delivers its maximum pressure ratio, and the surge margin is thus detrimental to the performance of the stage.

The flow phenomena that cause compressor surge are not yet well known. They need to be understood in order to drive design changes that can increase the operating range of the compressor. For the centrifugal compressors, several studies have identified the diffuser as a key zone for the inception of instabilities. In particular, large boundary layer separations may occur in this element as the operating point moves towards surge, leading to rotating stall and/or surge.

A number of investigations have then been done, trying to improve the surge margin using control techniques. Raw [1] demonstrated surge margin improvement by using "porous drilling" to bleed flow from the region of the diffuser throat. Spakovszky [2] demonstrated an improvement of the surge-margin when injecting air through the shroud surface of the vaneless space in the forward-tangent direction. Skoch [3] continued the investigations and demonstrated other techniques to extend the stable range of the same machine: reverse-tangent injection through the shroud surface of the vaneless space or retractable control tubes inserted through the shroud-side injectors openings. Then, he observed that each of the improvement techniques had the effect of reducing the diffuser leading edge incidence and concluded that reducing the average swirl angle across the span of the vaneless space as the compressor approached surge was the important control action and may be caused by the mere obstruction of the vaneless space due to presence of the injection nozzles.

In the same series of experiments, Skoch also evaluated the effects of hub-side injection into the diffuser throat, since PIV measurements had revealed a hub-corner stall on the pressure side of the vanes of the diffuser, that could suggest the use of air injection into the diffuser passage to energize the flow and control the separation. But these attempts did not demonstrate any significant surge-margin improvement [4]. The only slight effects were found to be due, as for 
shroud injection, to the obstruction caused by the injection nozzles and confirmed the previous conclusions made by Skoch about the importance of the angle at diffuser inlet.

The present work also focuses on the development of a control technique in order to extend the stable operating range of a centrifugal compressor. But instead of using injection, and decreasing the flow angle, it aims at controlling the separations that may occur, by using a boundary layer suction technique. That control action has indeed already been used in axial compressor stages or cascades and has provided attractive results [5-8].

An analysis of the flow is first presented, based on the solutions of both steady-state and unsteady simulations. Skin-friction patterns are drawn and reveal the topology of the flow.

Considering the localizations of the singular elements and separation skin-friction lines, an aspiration strategy is discussed and then implemented in the steady-state simulations. Several massflow rate removals are tested, and numerical performances of the aspirated compressor stage are presented.

\section{Test Case}

The test case is a centrifugal compressor stage manufactured by TURBOMECA, Groupe Safran, used for propelling helicopters, and that is representative of the present state of Turbomeca's technical know-how. It is composed of a backswept splitted unshrouded impeller, a radial vaned diffuser, and an axial diffuser. The relative Mach number at impeller leading edge at shroud is about 1 , whereas the flow in the diffuser is transonic. The axial diffuser is not taken into account in this study.

Experimental data used for computing the reference performance curves of the test case were provided by Turbomeca and were obtained during the characterization of the compressor stage. In particular, the static pressure was probed at the entry of the impeller, in the middle of the vaneless diffuser, and at the diffuser outlet. As an example, at the diffuser outlet, the experimental value of static pressure is the result of an average over 31 holes equally distributed along the circumference and all connected to the same annular chamber where the pressure is measured.

\section{Numerical Procedure}

Computations were performed with the elsA software developed at Onera. This code solves the compressible RANS equations by a cell-centered finite volume method. The turbulence model chosen for this study is the two-equation model of Smith (k-1), that was shown by Rochuon [9] and Trébinjac et al. [10] to provide results in a good accordance with the experiments in the case of a transonic centrifugal compressor stage. Both steady-state and unsteady numerical computations were performed.

For steady-state simulations, the mixing-plane approach is used for modeling the impeller-diffuser interaction, and the computation domain is reduced to one single passage per row thanks to a hypothesis of uniformity of flow within all passages.

For the unsteady simulations, a phased-lagged hypothesis is used. The main assumptions of the phase-lagged approach are the geometrical uniformity of the passages and the scrolling of the rotor blades in front of the stator blades as the unique source of flow temporal fluctuations. Under such conditions, there is only a phase difference between the states of passages, and computational domain may be reduced to a single passage per row.

The exit static pressure is set using a prescribed ratio between the pressure and the massflow values through the mesh exit section. This technique, in comparison with a classic simple prescription of the outlet static pressure, allows modeling the flow in the compressor stage beyond the peak of the compressor characteristic, that is necessary in order to study the limit of a compressor operating range, as pointed out by Hill IV [11].

In the elsA software, the prescribed ratio is respected thanks to an evolution of the outlet static pressure between two successive iterations according to the following relation:

$$
\begin{array}{r}
{\left[p_{s}\right]^{(n+1)}=\left[p_{s}\right]^{(n)} \times\left(1+\Lambda \times\left[\frac{\left[p_{s} / \dot{m}\right]^{(n)}}{\left[p_{s} / \dot{m}\right]^{(\mathrm{ref})}}-1\right]\right)} \\
\text { with } \Lambda \in[0 ; 1] .
\end{array}
$$

\section{Stage Mesh}

$\mathrm{H}, \mathrm{C}$, and $\mathrm{O}$ topologies are employed to create a structured multiblock mesh with the commercial meshing software Numeca Autogrid. The complete mesh is composed of 25 blocks, 18 of which describing the impeller geometry and 7 the diffuser. The tip clearance is meshed with an $\mathrm{O}-\mathrm{H}$ topology, in order to ensure a matching connection with the $\mathrm{C}$-mesh block around the impeller blade and the $\mathrm{H}$ behind its trailing edge. As for the vane of the diffuser, it is rounded by an O-block.

The number of points in the impeller tip clearance height is 21 .

Fillets are not included. That could be the point for some future extension of study.

The cell width at walls is set to $1 \mu \mathrm{m}$. That corresponds to a $y^{+}$parameter approximately equal to 1 along all solid surfaces.

Computations with a more refined mesh in the diffuser, including $4 \mathrm{e} 6$ points in the diffuser passage and a coarser one with only $4 \mathrm{e} 5$ in the diffuser passage, have also been performed in order to evaluate the mesh dependency of the numerical flow field and in particular of boundary layer separations that occur in the diffuser. Cell width at walls and mesh in the impeller passage have been kept the same.

Table 1 exposes the main dimensions of the meshes, the $\mathrm{H}$-blocks upstream of the impeller, and downstream of the diffuser being not taken into account. 
TABle 1: Main mesh dimensions without upstream and downstream H-blocks.

\begin{tabular}{lcc}
\hline & Impeller passage & $\begin{array}{c}\text { Diffuser passage } \\
\text { coarser/normal/refined }\end{array}$ \\
\hline Meridional direction & 217 & $73 / 141 / 277$ \\
Tangential direction & 137 & $37 / 81 / 153$ \\
Height direction & 81 & $65 / 77 / 89$ \\
\hline
\end{tabular}

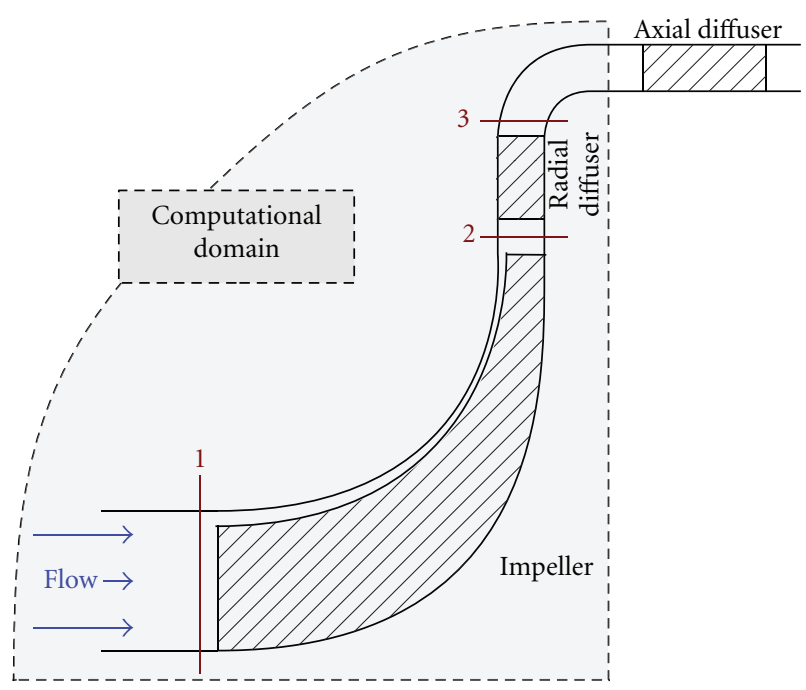

FIGURE 1: Numbering of planes used for performance computation.

\section{Performance Coefficients Computation}

In order to ensure that the flow fields resulting from the numerical simulations are valid, performance curves computed from numerical and experimental data are compared. The numbering of the planes used to express the results is shown in Figure 1. Planes 2 and 3 are planes at constant radius, located at the middle of the vaneless diffuser space and just downstream of the diffuser blade trailing edge, respectively.

When comparing experimental and numerical data, the static pressure numerical values are probed at exactly the same locations than the static pressure sensors. When comparing numerical results only, with and without aspiration, for example, the values are averaged in the entire plane, surface-weighted for static quantities and mass-weighted for total ones.

All performance coefficients are calculated assuming the following hypothesis.

(i) The area-averaged static pressure values in planes are supposed to be equal to the mean value between the hub static pressure and the shroud one. That allows to calculate total quantities from static pressure measurements at endwalls.

(ii) The Euler theorem is applied, assuming that the direction of the flow at the impeller inlet is perfectly axial. That is used in order to calculate the flow conditions at diffuser inlet.

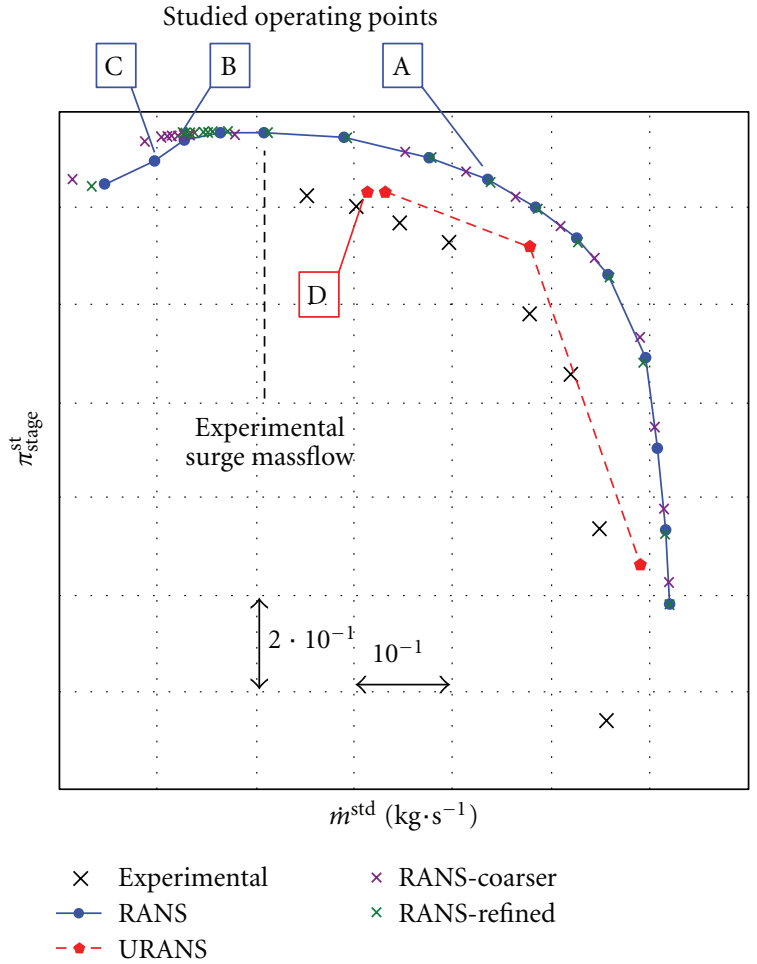

FIgURE 2: Total-to-static compressor stage pressure ratio.

One important parameter for characterizing the diffusion efficiency is the static pressure recovery coefficient of the diffuser stage. It is defined as the pressure rise through the diffuser divided by the inlet dynamic pressure:

$$
C_{p, 2-3}=C_{p, \text { diffuser }}=\frac{p_{s, 3}-p_{s, 2}}{P_{t, 2}-p_{s, 2}} .
$$

Performance data relating to the radial vaned diffuser are plotted as functions of the ratio (3); Rochuon [9] has demonstrated that this ensures the Mach number and the flow angle to be preserved at the diffuser inlet:

$$
c_{\text {impeller }}=\frac{\dot{m}^{\text {std }}}{\pi_{\text {impeller }}^{\text {st }}} .
$$

\section{Overall Performance}

Figures 2 and 3 give, respectively, the experimental and numerical total-to-static pressure ratio and the total-to-static isentropic efficiency of the impeller-diffuser compressor stage. Both steady and unsteady numerical results are plotted.

As already observed in a previous work [10], a better correspondence is obtained between experiment and unsteady simulations compared to the stationary ones. In particular, the steady-state computations overvalue the blockage massflow and the pressure ratio of the compressor stage. In addition, operating points that are fully acceptable under convergence criteria can be obtained for massflow much lower than the experimental surge massflow. A global stabilizing effect is due to the mixing-plane approach, to 


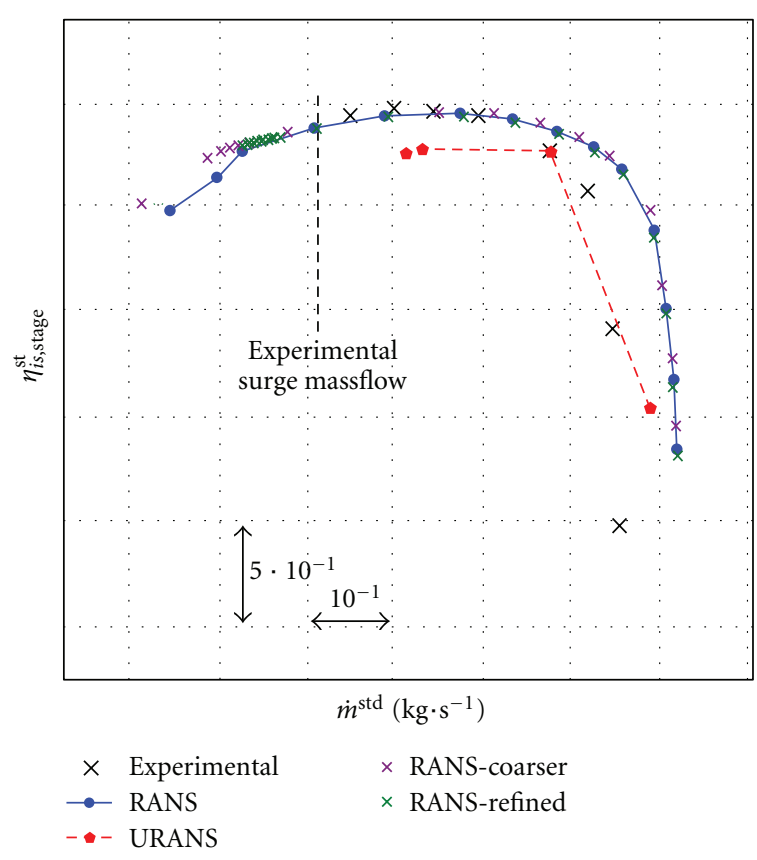

FIGURE 3: Total-to-static compressor stage isentropic efficiency.

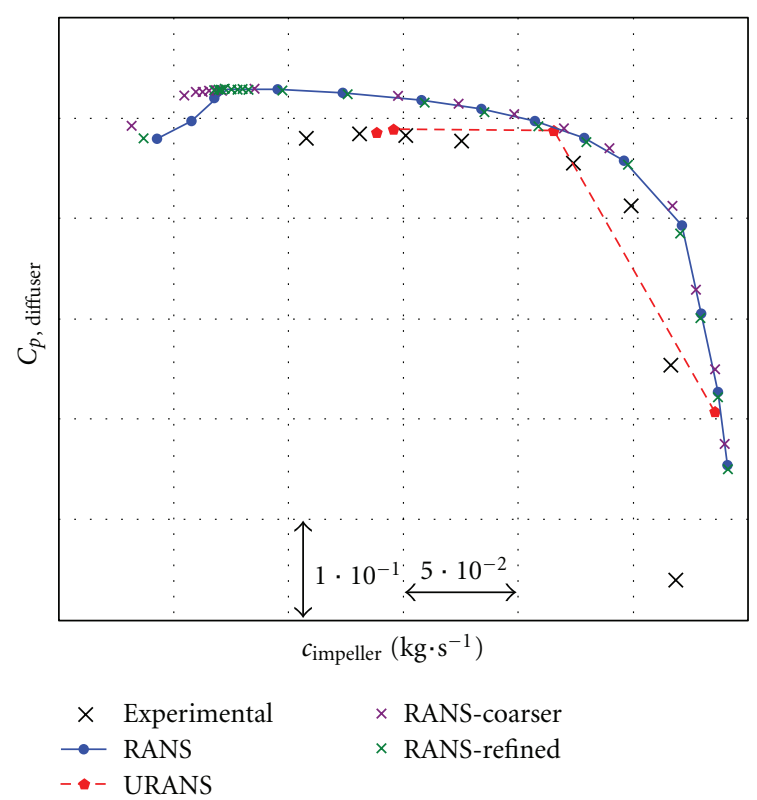

FIGURE 4: Diffuser static pressure recovery coefficient.

the hypothesis of uniformity between the rows passages, and to the evolution of the outlet boundary condition (1). That confirms the important role played by the time-dependent phenomena when reaching the limit of the stable operating range, especially for transonic compressors with small radial gap between impeller and diffuser, in which the flow is significantly affected by diffuser-impeller interactions.

Figure 4 shows the static pressure recovery through the radial vaned diffuser. Again, a better accordance of the URANS simulation with experiments has to be noticed.
Regarding the steady-state simulations, a sudden decrease of the diffuser static pressure recovery occurs when decreasing the massflow and suggests a stall of the diffuser vanes. With the coarser mesh, the decrease is less steep and is predicted at a lower massflow than with the two more refined meshes. However, the study of the flow topology does not reveal any significant difference in stall inception, which will be further presented, and the stall of the diffuser can be considered as mesh independent.

Even if the steady-state model is unable to predict correctly the surge massflow, flow structures that limit its stable numerical operating range can be analyzed, since convergence criteria are respected. Moreover, the existence of the boundary layer separation is also predicted by the phaselagged model.

A common method to analyze flow separations is the topological study of the skin-friction pattern [12], that can be experimentally observed using, for example, oil stream spread on the solid surfaces by the flow. The next section presents such a study applied on steady-state numerical flow fields. It highlights the growth of a boundary layer separation on the suction side of the diffuser vanes, finally leading to a complete stall when reaching the massflow corresponding to the breakdown of the static pressure recovery coefficient.

\section{Skin-Friction Pattern for Understanding 3D Flow Separations}

Since Prandtl [14] has shown that a two-dimensional flow separates from a no-slip boundary at points where the skin friction vanishes and admits a negative gradient, the comprehension of three-dimensional flow separations has been significantly improved. First, Legendre used the geometric theory of two-dimensional smooth vector fields in order to analyse the skin-friction patterns, locating the critical points and drawing the skin-friction trajectories [12]. The possible critical points are listed in Figure 5.

Later, Lighthill [15] proposed that the convergence of skin-friction lines is a necessary criterion for separation. Contrary to two-dimensional flows, separations occur in three dimensions along particular lines and not at points since the fluid can escape in the third direction. Délery [16] used this criterion in order to analyze a number of separated flow phenomena.

More recently, Surana et al. [13, 17, 18] demonstrated an exact theory of three-dimensional flow separations, taking into account the strength of the skin-friction lines convergence. They found in particular that only four types of separation lines-shown in Figure 6-can engender a unique and well-defined separation surface in physical flow fields. They also demonstrated, thanks to the hyperbolicity of the skin-friction lines, why a potential separation line may not lead to an effective three-dimensional separation.

In the following, the skin-friction patterns on wall surfaces in the diffuser are discussed for the operating points identified in Figure 2. The skin-friction lines are represented using the line integral convolution technique which is a filtering technique to locally blur texture along a vector field 


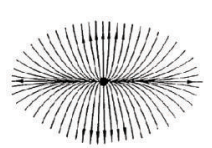

(a) Attachment node

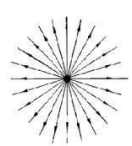

(b) Isotropic node

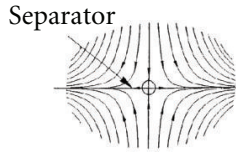

(c) Saddle point

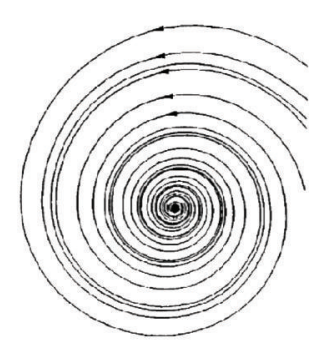

(d) Focus

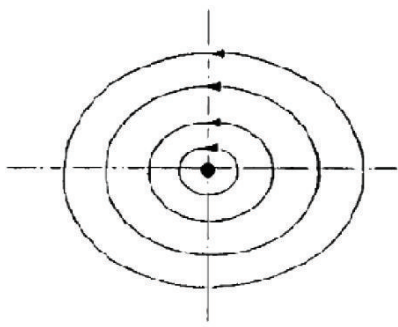

(e) Center
FIGURE 5: Critical points in skin-friction pattern (Délery [12]).

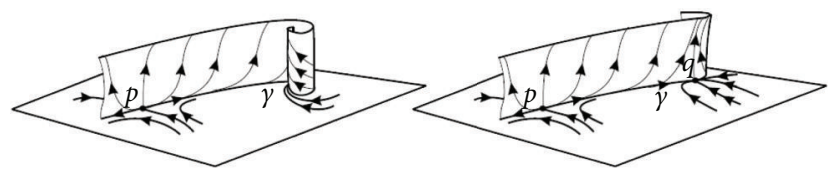

$(\mathrm{S} 1)$

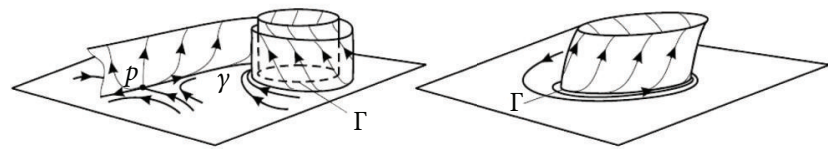

(S3)

(S4)

FIgURE 6: The four types of separation lines (Surana et al. [13]).

on a three-dimensional surface $[20,21]$. It gives visual results similar to the experimental oil streams visualization and is available in the open source software "Paraview" [22]. For clarity some of the skin-friction lines are enlightened.

\section{Analysis of the Flow within the Diffuser}

8.1. Steady-State Simulation Results. Figure 8 shows the topology of the flow on pressure and suction sides of the diffuser vanes for the three operating points labeled A, B, and $\mathrm{C}$ in Figure 2.

At the nominal operating point A, a particular flow pattern is located on the pressure side surface near shroud. It is not a separation: the node $N_{\mathrm{PS}, 1}$ is the mark of the impact of flow on the pressure surface, of which a part goes upstream toward the saddle $S_{\mathrm{PS}, 1}$. This saddle $S_{\mathrm{PS}, 1}$ originates the separation line between the core and the reverse flows and expresses the confrontation between these two parts of flow.

On the vane suction side, two saddles are located in the hub and shroud corner and correspond to the location of the maximal adverse pressure gradient, that is, the diffuser throat. These saddles separate the core flow from the reverse flow in the corners, which may be strengthened by the

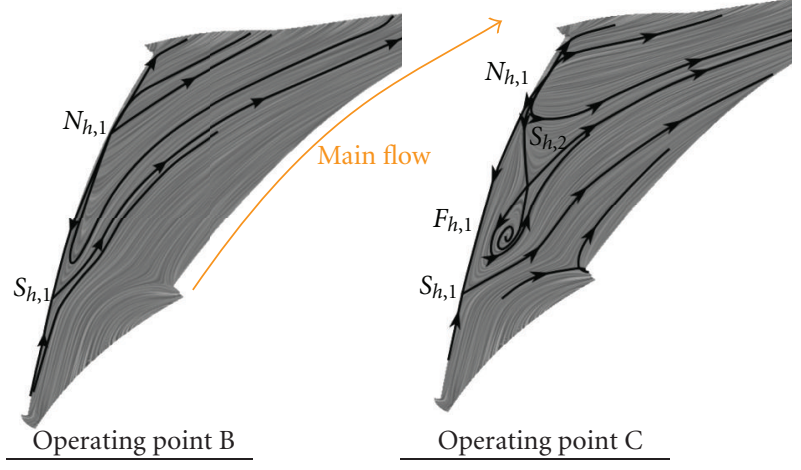

Figure 7: Hub skin-friction pattern.

modeling of corners as sharp edges instead of smooth fillets. A further comparison should allow to specify their influence.

At maximal pressure ratio operating point $\mathrm{B}$, the reattachment line $N_{\mathrm{PS}, 1}-S_{\mathrm{PS}, 1}$ on pressure side disappeared. On the other hand, a reverse flow area grows on the suction side and is separated from the core flow by a separation line emanating from a saddle $S_{\mathrm{SS}, 1}$, located at the maximum adverse pressure gradient area, corresponding to the diffuser throat. The skin-friction lines in the bottom quarter of vane height are now captured by a separation focus $F_{\mathrm{SS}, 1}$. Another saddle $S_{\mathrm{SS}, 3}$ separates the skin-friction lines captured by $F_{\mathrm{SS}, 1}$ from these going toward downstream.

When decreasing more the massflow rate, the focus $F_{\mathrm{SS}, 1}$ enlarges and the flow on the half bottom of the diffuser vane is separated. But the main change in the topology of the flow when reaching the stalled configuration concerns the hub surface, represented in Figure 7. The separation line between the core flow and the reverse flow coming from $N_{h, 1}$, that emanates from the saddle $S_{h, 1}$, straightens up across the passage, and a reattachment focus $F_{h, 1}$ appears, fed by the vane suction surface detachment focus $F_{\mathrm{SS}, 1}$. Before the stall, the vortex emanating from the focus $F_{\mathrm{SS}, 1}$ is convected toward downstream by the core flow, whereas at the stalled operating point, it swoops down on the hub surface. Threedimensional streamlines that put into evidence this stalled topology are represented in Figure 11.

One should notice that the stalled topology differs from the one widely called as "corner stall," and described in the work of Lei et al., for example [19]. In the case of a corner stall, $F_{S S, 1}$ and $F_{h, 1}$ would be both detachment focuses, meaning that boundary layers on hub and suction surfaces would both separate at the same location (Figure 9). For the topology studied in this paper, only the suction-side boundary layer separates, and the reversal flow on the hub surface is a consequence of that separation, since flow that escapes from the vane suction side spreads on the hub. In addition, classic hub-corner stall in Figure 9 may be explained by an accumulation of low-momentum fluid in the corner, under the action of the secondary flows.

In the present case, the growth of the corner separation in the hub corner is explained by the cross flow: the overdeviation of the flow near the walls at impeller outletsee Figure 10-leads to a spanwise distortion of the diffuser 

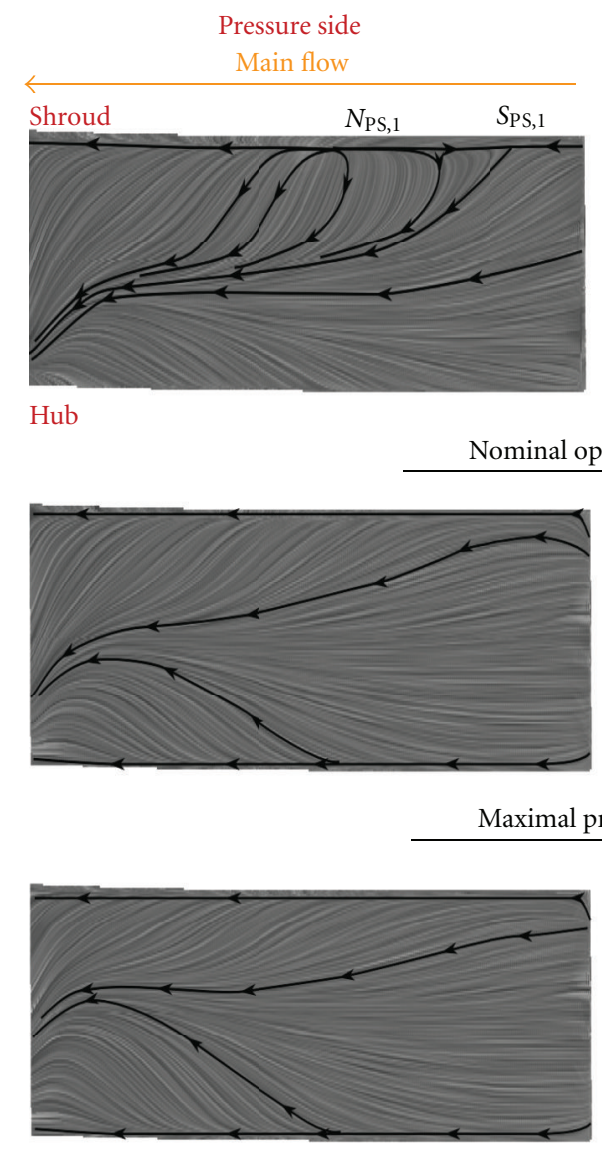

Stalled configuration "C"

$S_{S S, 1}$

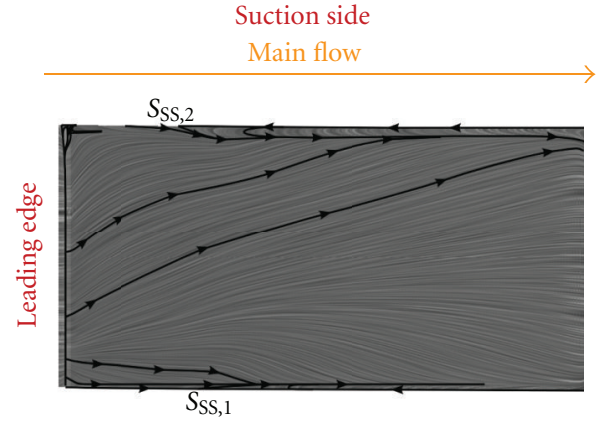

$S_{S S, 1}$
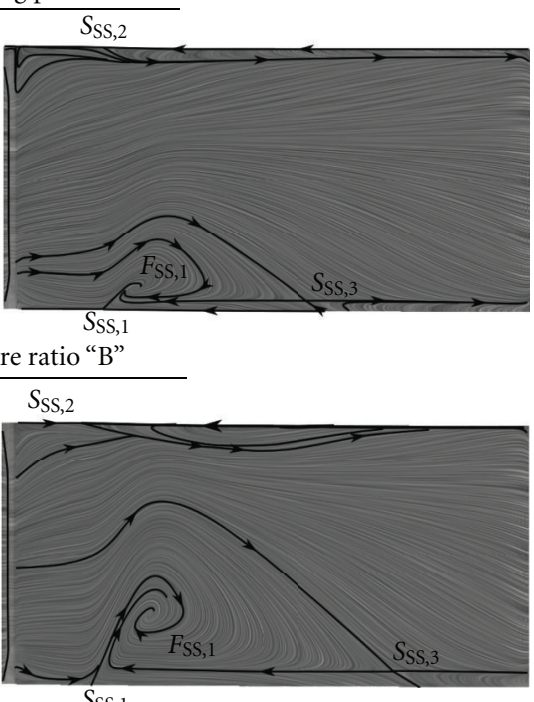

"

FIGURE 8: Skin-friction patterns on pressure and suction sides of diffuser vanes.

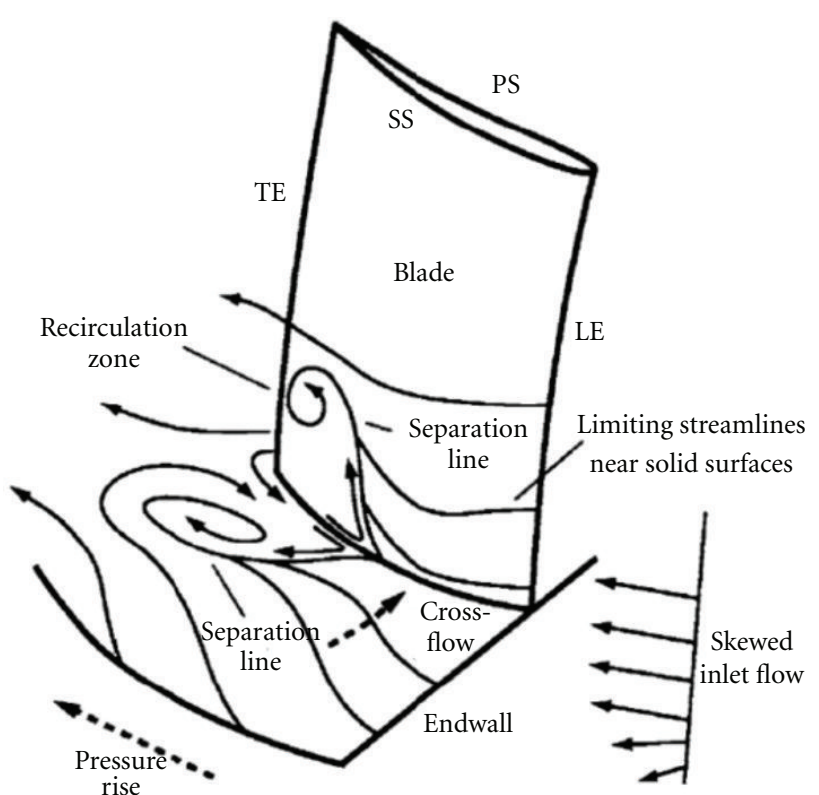

FIGURE 9: Hub-corner stall-limiting streamlines and separation lines (Lei et al. [19]). flow incidence. The overincidence due to the wake (of the jetwake flow structure, that is, near the shroud surface) is more pronounced than the overincidence due to the hub boundary layer: that leads to a powerful vortex that carries the flow on the vane suction side from the hub toward the shroud (Figure 12).

8.2. Time-Averaged Numerical Flow Field. In order to confirm the existence of the boundary layer separation in the diffuser, the time-averaged flow field coming from the unsteady calculation labeled as D in Figure 2 is considered. The topology of the flow is analyzed and compared to the steady-state one.

Figure 13 exposes skin-friction lines and streamlines for the time-averaged flow field at operating point $\mathrm{D}$. The unsteady model also predicts the boundary layer separation in the diffuser hub-suction side corner. Moreover, the main saddle $S_{\mathrm{SS}, 1}$ is located at the same location as in steady-state simulations, that is, at the diffuser throat. But the separated zone is more extended, since the saddle $S_{\mathrm{SS}, 3}$ - which is the downstream boundary of the separated zone-is almost on the trailing edge of diffuser vane. 


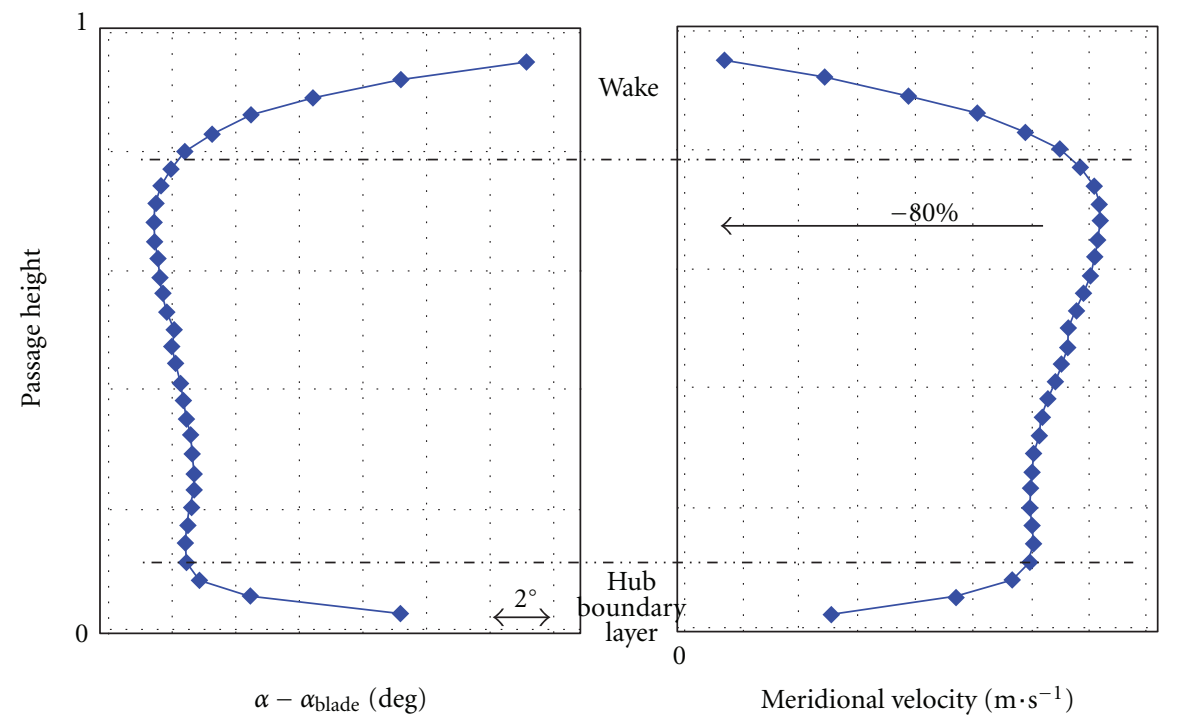

FIgURE 10: Flow conditions at diffuser inlet operating point B.
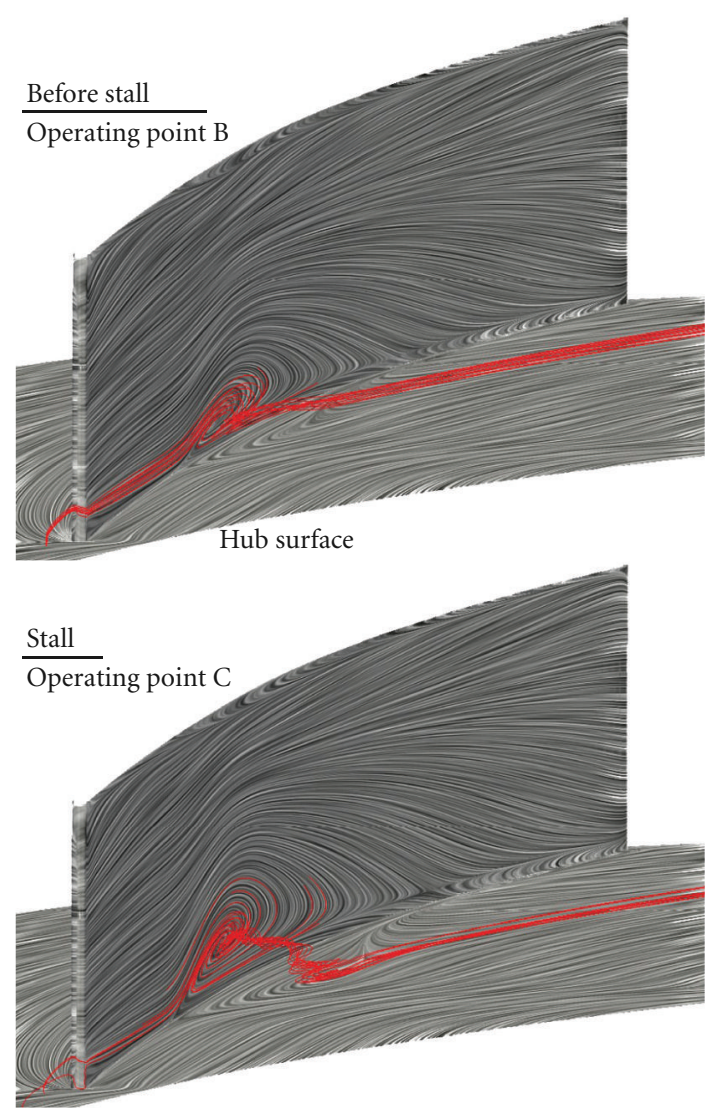

FIGURE 11: Hub-suction side corner separation 3D streamlines.

In addition, a skin-friction pattern including two focuses on both suction and hub surfaces, like the steady stalled one, is periodically observed when looking at the temporal evolution of the skin-friction pattern predicted by the unsteady simulations (Figure 14).

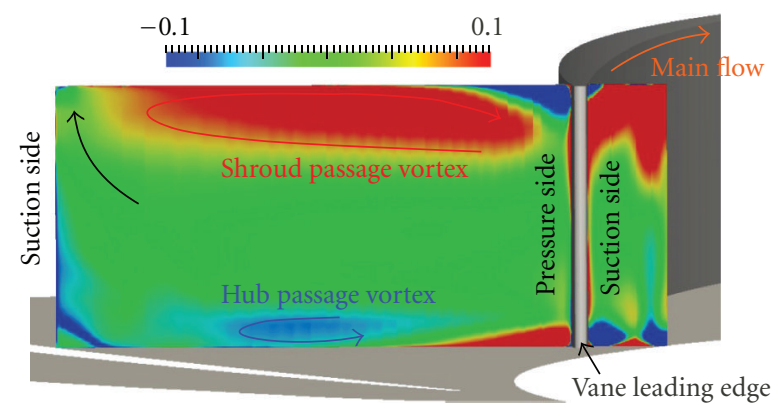

FIgURE 12: Helicity in a section across diffuser passage.

That agreement in flow topology coming from steady and unsteady calculations gives confidence in the boundary layer separation prediction and in the fact that the compressor stable operating range is actually limited by a stall of the radial diffuser vanes.

Then, a control technique aiming at avoiding the diffuser stall and then extending the compressor operating range is developed.

\section{Aspiration Strategy}

9.1. Location of Suction Device. In two dimensions, Miller and Chapman [23] have determined that suction should be introduced around the separation point, that can be identified thanks to the zero of the skin-friction coefficient, in order to be the most efficient with the minimum of fluid removal. This zone, schematized in Figure 15, is located at the intersection between the solid surface and the line separating the reverse and the core flow.

In three dimensions, main and reverse flows are separated by a three-dimensional surface, whose intersection with the solid wall is a separation line of one of the four types 


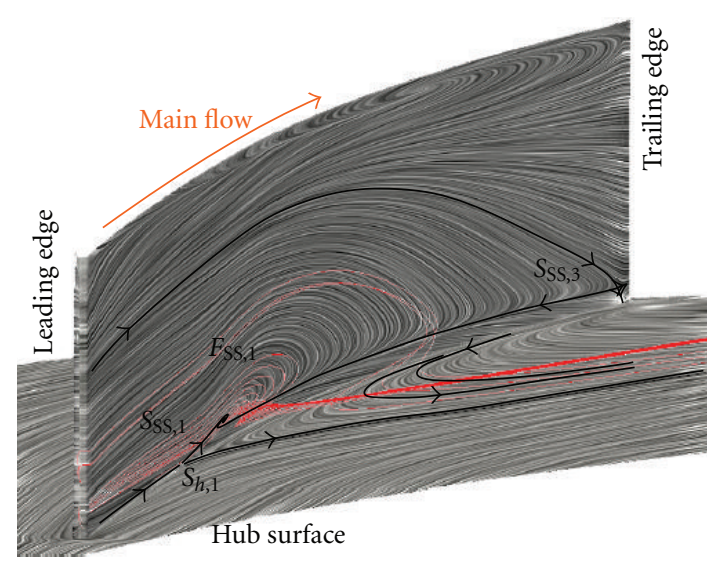

- 3D streamlines

$\rightarrow$ Skin-friction lines

FIGURE 13: Evidence of a boundary-layer separation time-averaged flow field; operating point D.

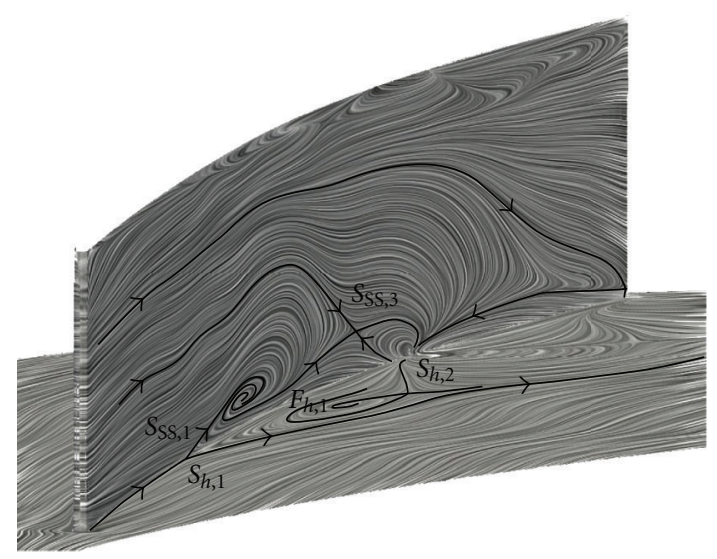

FIGURE 14: Snapshot of the time-varying skin-friction pattern. Existence of a two-focus topology; operating point D.

in Figure 6. This line should be then considered for the development of the aspiration strategy. Considering the stalled skin-friction pattern in Figure 7, the main separation line appears to be the $S_{S S, 1}-F_{S S, 1}$ skin-friction line. The suction slot should then be located in the region of the seeds $S_{S S, 1}=S_{h, 1}$, that originates the frontier surface between the core and the reverse flow.

9.2. Numerical Modeling of Aspiration. Two ways for modeling the effect of the suction device on the flow have been evaluated.

(i) The first uses a boundary condition in order to set a surface massflow through the faces of the mesh cells at wall included in the suction slot. This technique is quite easy to use. The precision of the suction slot geometrical description depends on the density of the mesh, that is, the size of the faces describing the hub solid surface.

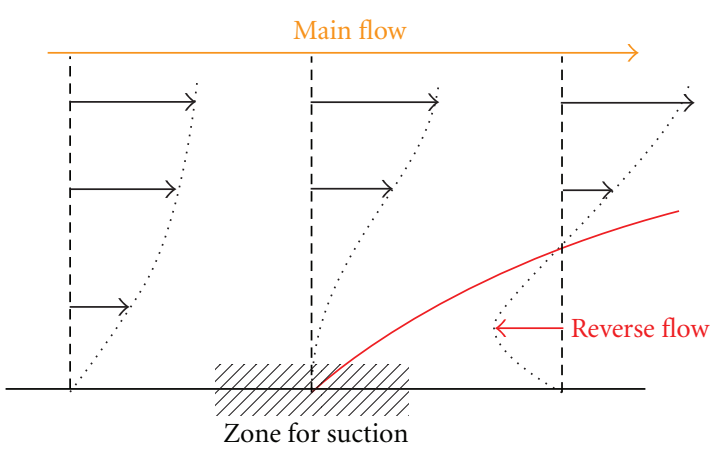

FIGURE 15: Location of suction-2D approach.

(ii) The second is known as "chimera technique" and is available in the elsA software. This one allows to stack up two or more meshes, in order to model complex geometries using a basic mesh and others more refined describing the solid boundary, back and forth interpolations being done between the stacked meshes. It is now used in a wide range of applications for modeling the technological effects in turbomachinery [24]. The chimera technique involves the meshing of the aspiration slot, whose shape must then be considered.

In this paper, the study of the most efficient shape for suction slot is not a priority. The main aim is to explore the effect of a fluid removal on the performance of the compressor stage and on the flow topology within the diffuser. Then, the first approach for modeling the suction slots is appropriate.

The second modeling was also tested, using a common shape for slot, without fillets, in order to validate the results obtained with the boundary condition technique.

\subsection{Tested Aspiration Device. Different implementations of} suction have been tested:

(i) a removal of 1 percent of the experimental surge massflow, through the hub surface, along the vane, using boundary limit condition,

(ii) the same removal of 1 percent of the experimental surge massflow, at the same location, using the chimera technique,

(iii) a removal of 0,3 percent of the experimental surge massflow rate through the hub surface, with a reduced slot surface compared to the previous case, in order to keep the slot surface massflow constant. The upstream edge of the suction slot is also kept at the same location,

(iv) a removal of 0,3 percent of the experimental surge massflow, through the vane suction side, keeping again the slot surface massflow constant,

(v) a removal of 0,1 percent of the experimental surge massflow, through the same suction slot shape as the $0,3 \%$ hub-suction case. The slot surface massflow is then reduced, 


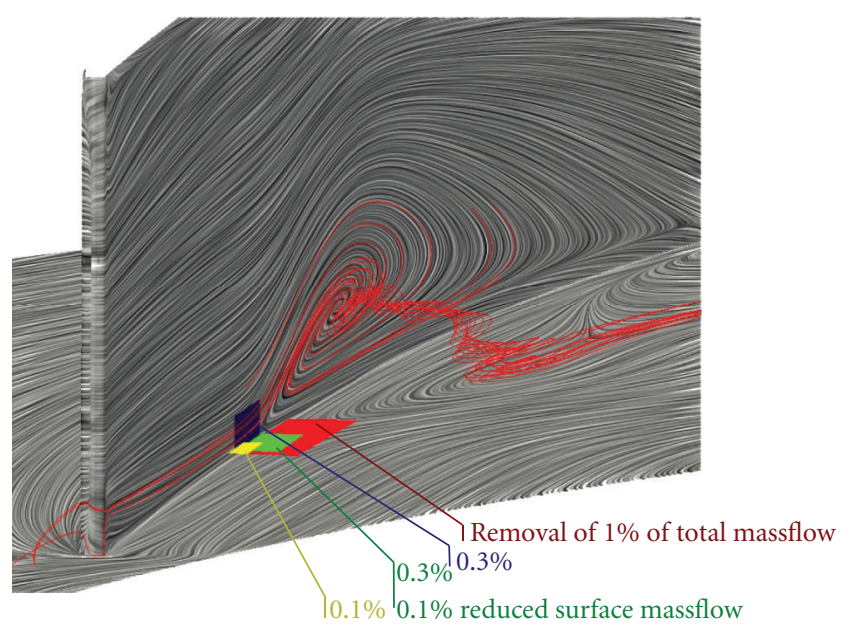

FIGURE 16: Locations of suction slots and percentage of removed massflow; operating point $\mathrm{C}$.

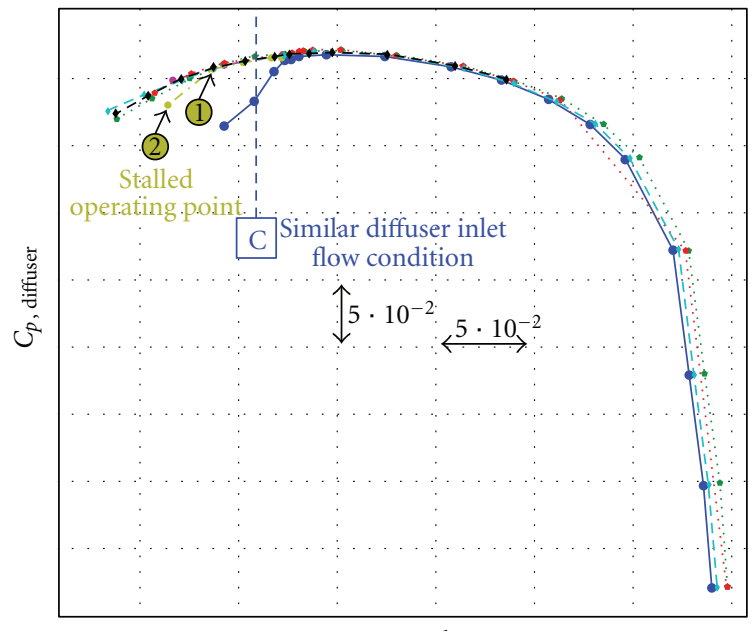

$c_{\text {impeller }}\left(\mathrm{kg} \cdot \mathrm{s}^{-1}\right)$

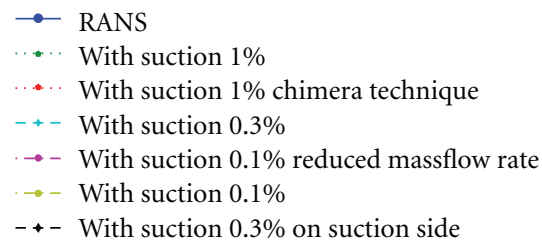

Figure 17: Static pressure recovery coefficient of aspirated diffuser.

(vi) a removal of 0,1 percent of the experimental surge massflow through a smaller suction slot, so that the slot surface massflow is the same as the case of $0,3 \%$ hub suction.

Figure 16 summarizes the various tested cases, superimposed on the skin-friction topology of the flow at operating point $\mathrm{B}$.

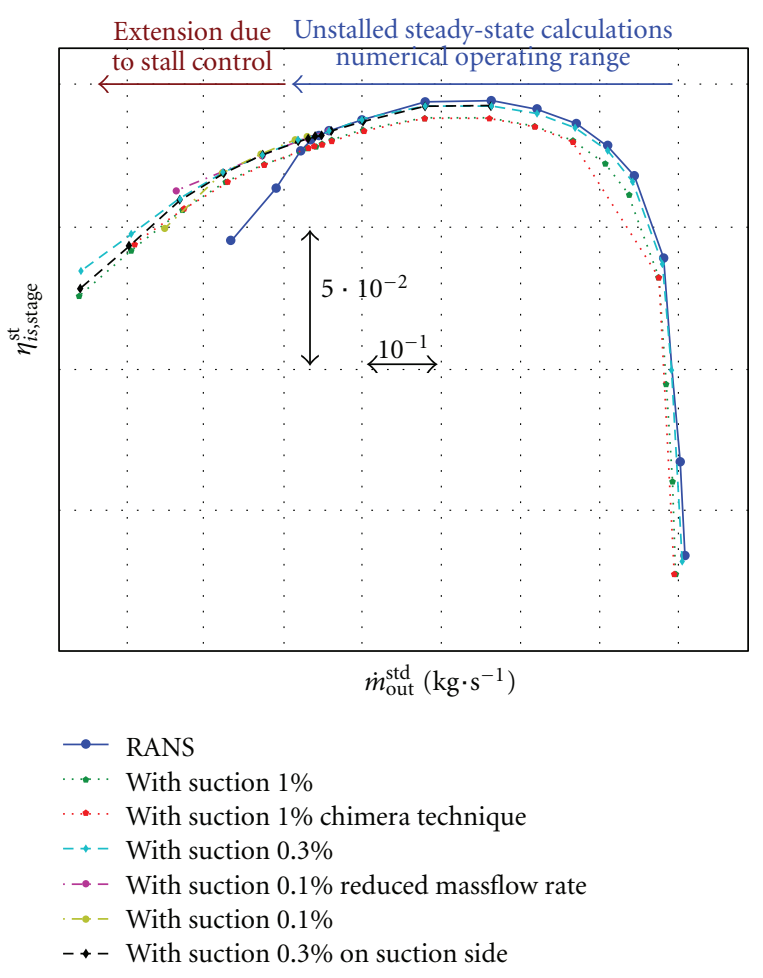

FIGURE 18: Isentropic efficiency of the aspirated compressor stage.

\section{Aspirated Compressor Stage}

10.1. Global Performance (Steady-State Calculations). Figure 17 shows the static pressure recovery coefficient of the aspirated diffuser. For comparison, the base case is plotted again.

Figure 18 shows the total-to-static isentropic stage efficiency taking into account the removed massflow defined by (4) as a function of the standard stage outlet massflow defined by (5):

$$
\begin{aligned}
& \widetilde{\eta}_{\text {is stage }}^{\mathrm{st}}=\frac{\left(1-c_{m s}\right)\left(\pi_{\text {stage }}^{\mathrm{st}}(\gamma-1) / \gamma-1\right)}{T_{t, \text { out }} / T_{t, \text { in }}-1}, \\
& \dot{m}_{\text {out }}^{\text {std }}=\dot{m}_{\text {out }} \times \sqrt{\frac{T_{t, \text { in }}}{T_{t, \text { ref }}}} \times \frac{P_{t, \text { ref }}}{P_{t, \text { in }}} .
\end{aligned}
$$

The $\left(1-c_{m s}\right)$ factor in (4) signifies that a perfect isentropic transformation would only compress the amount of flow thrown out at diffuser outlet, without taking the removed massflow into account.

The influences of the aspiration devices on the performance of the stage are predominant for operating points at lowest massflow. The main effect is the withdrawal of the drop of the diffuser static pressure recovery coefficient, the impeller working under the same conditions as without aspiration. Efficiency decrease is moderate and is mainly due to $\left(1-c_{m s}\right)$ factor, that is, to the wasted compressed flow. It obviously becomes negligible for the $0,3 \%$ and $0,1 \%$ aspirated cases. 

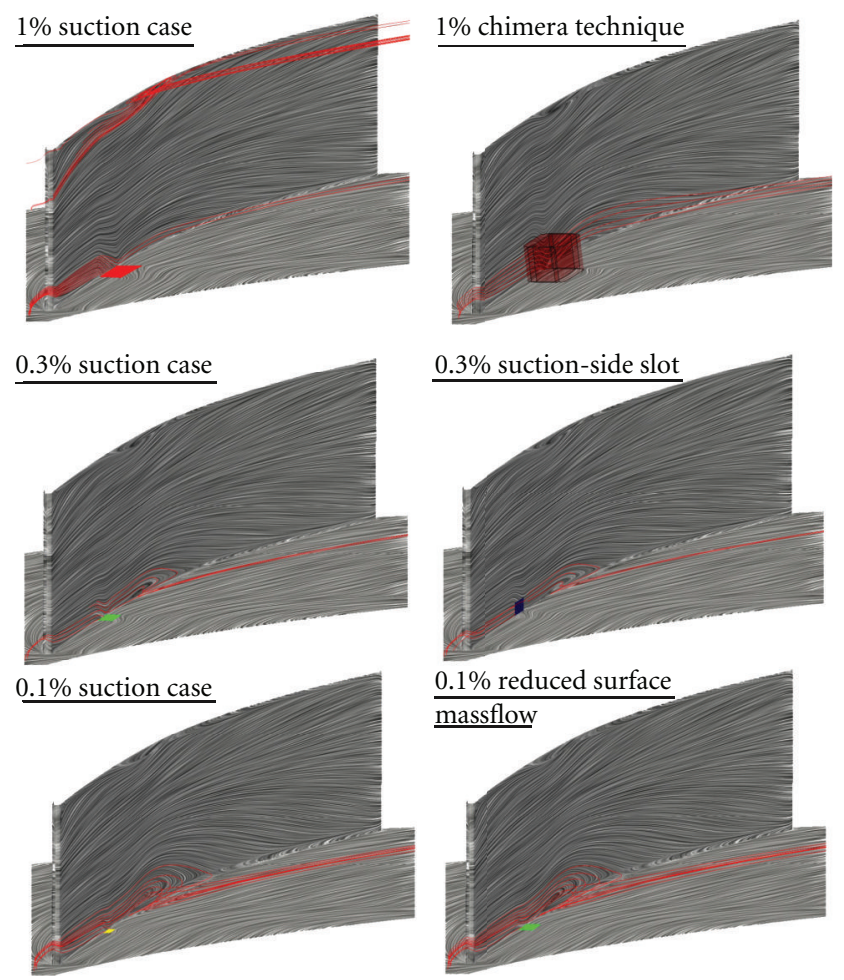

FIGURE 19: Skin-friction patterns for the different aspirated diffusers.

Chimera and boundary limit conditions techniques give both similar results, ensuring the validity of exploring the effect of suction by using the boundary limit condition technique, prior to designing an optimal suction slot.

The vane suction-side suction slot does not improve the performance more than the other configurations and should then be avoided for technical reasons, due to the vane thickness.

In conclusion, the suction technique seems to be a promising way in order to control the stall of the diffuser static pressure recovery. An analysis of the skin-friction pattern within the aspirated diffuser allows to study more precisely the effect of aspiration on flow field.

10.2. Skin-Friction Patterns with Aspiration. Figure 19 exposes the skin-friction patterns for the different aspirated cases. In all cases, the inlet diffuser flow conditions are similar to that of operating point $\mathrm{C}$ because the ratio (3) is the same (Figure 17).

For the $1 \%$ suction cases, the boundary layer separation in the hub-vane suction side corner region is completely removed. Even for the operating point at lowest massflow on Figure 18, no separation occurs. However, a separation focus appears in the shroud-vane suction corner. That observation is in accordance with the absence of any increase in the diffuser static pressure recovery, in spite of the hub-corner boundary layer separation removal. Indeed, the boundary layer separation has switched to another zone, meaning that the fluid is at its maximal diffusion capacity and cannot remain attached on all the walls simultaneously. But the shroud-corner separation seems to be less critical for the numerical stability. Fully stall-free converged operating points can obtain much lower massflows than the lowest massflow of the base case.

Chimera technique gives similar results, only excepting a small vortex created at the slot downstream edge, which highlights the necessity of an optimization process of the suction slot shape; that is however not a matter of concern for now.

The $0,3 \%$ aspirated cases do not achieve a complete control of the hub-corner boundary layer separation and only diminish its extent. Hub and suction-side aspirations have the same effect on the flow field; in particular, the extent of the separation is similarly reduced.

Concerning the $0,1 \%$ aspirated cases, the hub-corner boundary layer separation is even less reduced. But the interesting thing is that, at this operating point, the two suction slots lead to a similar effect on the flow, despite the different surface massflows. The total amount of removed fluid is then thought to be the determinant parameter in this case, and not the slot surface massflow.

However, when decreasing more the stage massflow, the degeneration of the separation into a massive stall is not avoided using the smallest suction slot. Figure 20 shows the flow topology for the two operating points marked 1 and 2 in Figure 17. In case 2, the main separating saddle $S_{\mathrm{SS}, 1}$ is located just downstream of the suction slot; its inability to delay the stall more is thought to be due to its location, and highlights the sensitivity of the control efficiency to that parameter, especially when the slot is small sized. 


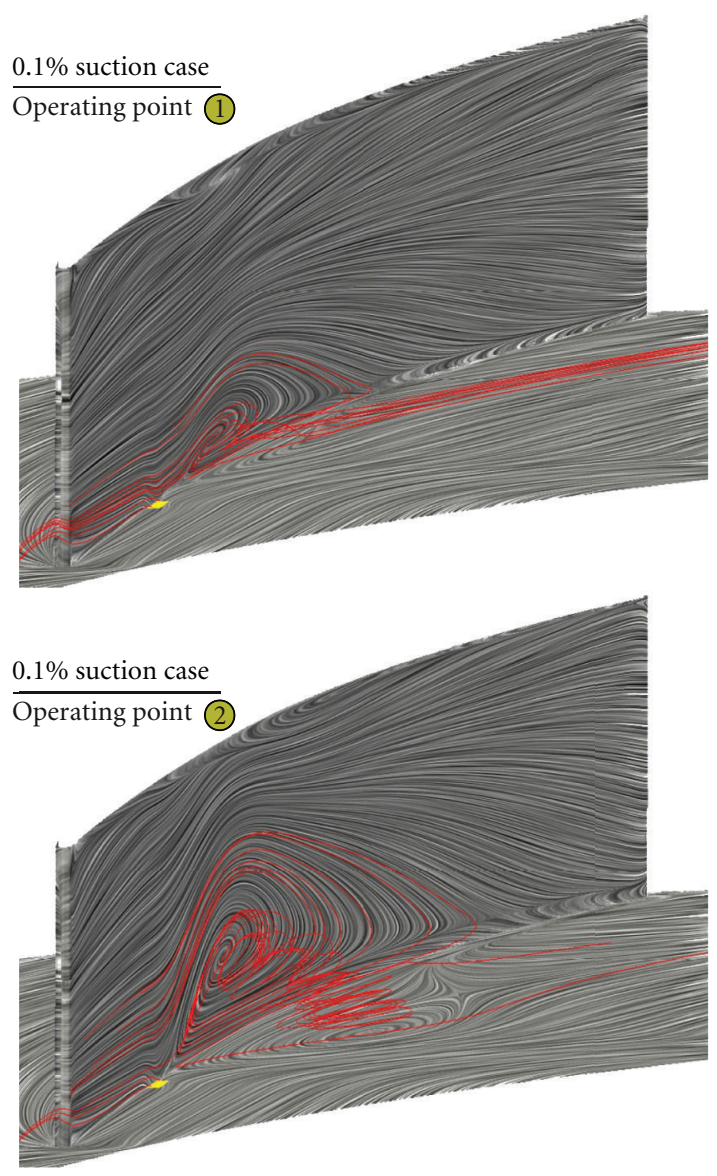

Figure 20: Stall of the $0,1 \%$ aspirated diffuser.

And the amount of fluid removal was thought to be the determining factor, not the slot surface massflow.

In spite of these encouraging results, it is well known that the unsteadiness plays a leading role in case of transonic centrifugal compressors operating near surge. The aspiration technique-whose development has been based on the results of steady-state model, that stabilizes operating points for massflows lower than the experimental surge massflowshould then be implemented in unsteady calculations in order to ensure its efficiency and the increase of the operating range.

The validity of single-passage calculations should also be examined, since it may have a stabilizing effect on the numerical simulations, maybe as important as the timedependent effects due to impeller-diffuser interaction.

The influence of the fillets on the flow topology should also be evaluated in future work, since it may modify the adequate location of the suction slot.

The major role played by the vortex created by the overincidence on diffuser vane near the shroud was also pointed out by the present study. It may then be interesting to evaluate other design techniques, that would take that observation into account. In particular, the vane of the studied diffuser is of $2 \mathrm{D}$ shape, with a leading edge that is just a line parallel to axis of revolution, and the hub wall is of planar shape. Studies have already shown that potential improvements could be obtained thanks to a redesign of the diffuser leading edge $[25,26]$. A passive control strategy of the hub boundary layer separation, based on geometrical modifications of the diffuser vane and hub shapes, without any waste of compressed flow, should then be investigated.

\section{Nomenclature}

\section{Summary and Prospects}

A skin-friction pattern investigation within a radial vaned diffuser, aiming to highlight the flow phenomena limiting the stable operating range, has revealed the growth of a boundary layer separation in the diffuser hub-suction side corner. When reaching the numerical stability limit, that boundary layer finally led to a fully stalled flow pattern, causing a dropdown of the diffuser static pressure recovery coefficient and thus of the global compressor stage performances.

The existence of that boundary layer separation was confirmed by phase-lagged models results.

Taking into account the location of the skin-friction pattern critical points, a boundary layer suction technique was developed. The main separation saddle was located, and the suction slot was placed in its vicinity.

Several cases were tested, and an effective control of the diffuser stall has been reached with a removal of only $0,1 \%$ of the total stage massflow. From a steady-state point of view, that effective control has led to an increase by $40 \%$ of the stall-free diffuser operating range.

Comparison between the various suction configurations has not revealed any significant differences between the results obtained with a hub or a suction-side suction slot.
PS, SS:

$\dot{m}:$

$\dot{m}^{\text {std }}$ :

Blade pressure side, suction side

Massflow

Corrected massflow for impeller inlet at standard conditions

$\pi_{\text {impeller }}^{\text {st }}: \quad \quad$ Impeller static pressure ratio

$C_{p \text {,diffuser: }} \quad$ Static pressure recovery coefficient of the diffuser

$p_{s}: \quad$ Static pressure

$T_{t}: \quad$ Total temperature

$P_{t}: \quad$ Total pressure

$\omega: \quad$ Impeller rotational speed

$\alpha: \quad$ Absolute flow angle

$N_{s}=\omega \sqrt{\dot{m}} / \Delta H^{3 / 4}$ : Compressor specific speed

$[\cdots]^{(n)}: \quad$ Value at the $n$th calculation step.

\section{Acknowledgments}

The authors would like to thank Turbomeca, Groupe Safran, which supported this research. Thanks also go to the French Aerospace laboratories, Onéra, that provides the numerical code, elsA, and to the Agence Nationale de la Recherche et de la Technologie that promotes the collaboration between research laboratories and industrialists. 


\section{References}

[1] J. A. Raw, "Surge margin enhancement by a porous throat diffuser," Canadian Aeronautics and Space Journal, vol. 32, no. 1, pp. 54-60, 1986.

[2] Z. S. Spakovszky, "Backward traveling rotating stall waves in centrifugal compressors," Journal of Turbomachinery, vol. 126, no. 1, pp. 1-12, 2004.

[3] G. J. Skoch, "Experimental investigation of centrifugal compressor stabilization techniques," Journal of Turbomachinery, vol. 125, no. 4, pp. 704-713, 2003.

[4] G. J. Skoch, "Experimental investigation of diffuser hub injection to improve centrifugal compressor stability," Journal of Turbomachinery, vol. 127, no. 1, pp. 107-117, 2005.

[5] J. L. Kerrebrock, A. H. Epstein, A. A. Merchant et al., "Design and test of an aspirated counter-rotating fan," Journal of Turbomachinery, vol. 130, no. 2, Article ID 021004, 2008.

[6] A. Sachdeva, Study and control of three-dimensional flow separations in a high pressure compressor stator blade row with boundary layer aspiration [Ph.D. thesis], Ecole Centrale de Lyon, 2010.

[7] A. Godard, Etude numerique et experimentale d'un compresseur aspire [Ph.D. thesis], Ecole Centrale de Lyon, 2010.

[8] J. L. Kerrebrock, "Aspirated compressors = shorter and lighter engines: a boon for supercruising jets," Aero-Astro, (2), 2005, http://aeroastro.mit.edu/news-events/aeroastro-annualreport.

[9] N. Rochuon, Analyse de l'écoulement tridimensionnel et instationnaire dans un compresseur centrifuge à fort taux de pression [Ph.D. thesis], Ecole Centrale de Lyon, 2007.

[10] I. Trébinjac, P. Kulisa, N. Bulot, and N. Rochuon, "Effect of unsteadiness on the performance of a transonic centrifugal compressor stage," Journal of Turbomachinery, vol. 131, no. 4, Article ID 041011, 9 pages, 2009.

[11] R. A. Hill IV, Simulation of spike stall inception in a radial vaned diffuser [Ph.D. thesis], Massachusetts Institute of Technology, 2007.

[12] J. M. Délery, "Robert legendre and henri werlé: toward the elucidation of three-dimensional separation," Annual Review of Fluid Mechanics, vol. 33, pp. 129-154, 2001.

[13] A. Surana, G. B. Jacobs, O. Grunberg, and G. Haller, "An exact theory of three-dimensional fixed separation in unsteady flows," Physics of Fluids, vol. 20, no. 10, Article ID 107101, 2008.

[14] L. Prandtl, "Flüssigkeit bei sehr kleine Reibung," Verhandlungen des dritten internationalen mathematischen Kongresses, Heidelberg, Germany, 1904, http://webdoc.sub.gwdg.de/univerlag/2010/GKSM3.pdf.

[15] M. J. Lighthill, Attachment and Separation in Three-Dimensional Flow, Laminar Boundary Layers, Oxford University Press, 1963.

[16] J. M. Délery, “Topologie des écoulements tridimensionnels décollés stationnaires: points singuliers, séparatrices et structures tourbillonnaires," Onéra, Département d'Aérodynamique Fondamentale et Expérimentale, 1999.

[17] A. Surana, O. Grunberg, and G. Haller, "Exact theory of three-dimensional flow separation. Part 1. Steady separation," Journal of Fluid Mechanics, vol. 564, pp. 57-103, 2006.

[18] A. Surana, G. B. Jacobs, O. Grunberg, and G. Haller, "An exact theory of three-dimensional fixed separation in unsteady flows," Physics of Fluids, vol. 20, no. 10, Article ID 107101, 22 pages, 2008.
[19] V. M. Lei, Z. S. Spakovszky, and E. M. Greitzer, "A criterion for axial compressor hub-corner stall," in Proceedings of the ASME 51st Turbo Expo, pp. 475-486, May 2006.

[20] B. Cabral and L. Leedom, "Imaging vector fields using line integral convolution," in Proceedings of the 20th annual conference on Computer graphics and interactive techniques (ACM '93), pp. 263-270, New York, NY, USA, August 1993.

[21] A. Sundquist, "Dynamic line integral convolution for visualizing streamline evolution," IEEE Transactions on Visualization and Computer Graphics, vol. 9, no. 3, pp. 273-282, 2003.

[22] Paraview UsersGuide 3.14, Kitware, 2012, http://www.paraview.org/paraview/resources/software.php.

[23] M. L. Miller and D. C. Chapman, "Single-stage experimental evaluation of boundary layer bleed techniques for high lift stator blades," NASA, CR-54569, 1968, http://www.archive.org/ details/nasa_techdoc_19680019149.

[24] L. Castillon, G. Billonnet, S. Péron, and C. Benoit, "Numerical simulations of technological effects encountered on turbomachinery configurations with the chimera technique," in Proceedings of 27th International Congress of the Aeronautical Sciences, Nice, France, 2010.

[25] E. Casartelli, A. P. Saxer, and G. Gyarmathy, "Numerical flow analysis in a subsonic vaned radial diffuser with leading edge redesign," Journal of Turbomachinery, vol. 121, no. 1, pp. 119126, 1999.

[26] Z. Palat, "Design Optimization and Test of Advanced Small Scale Compressor," NEWAC Workshop 2010, Munich, Germany, 2010, http://www.newac.eu/88.0.html. 

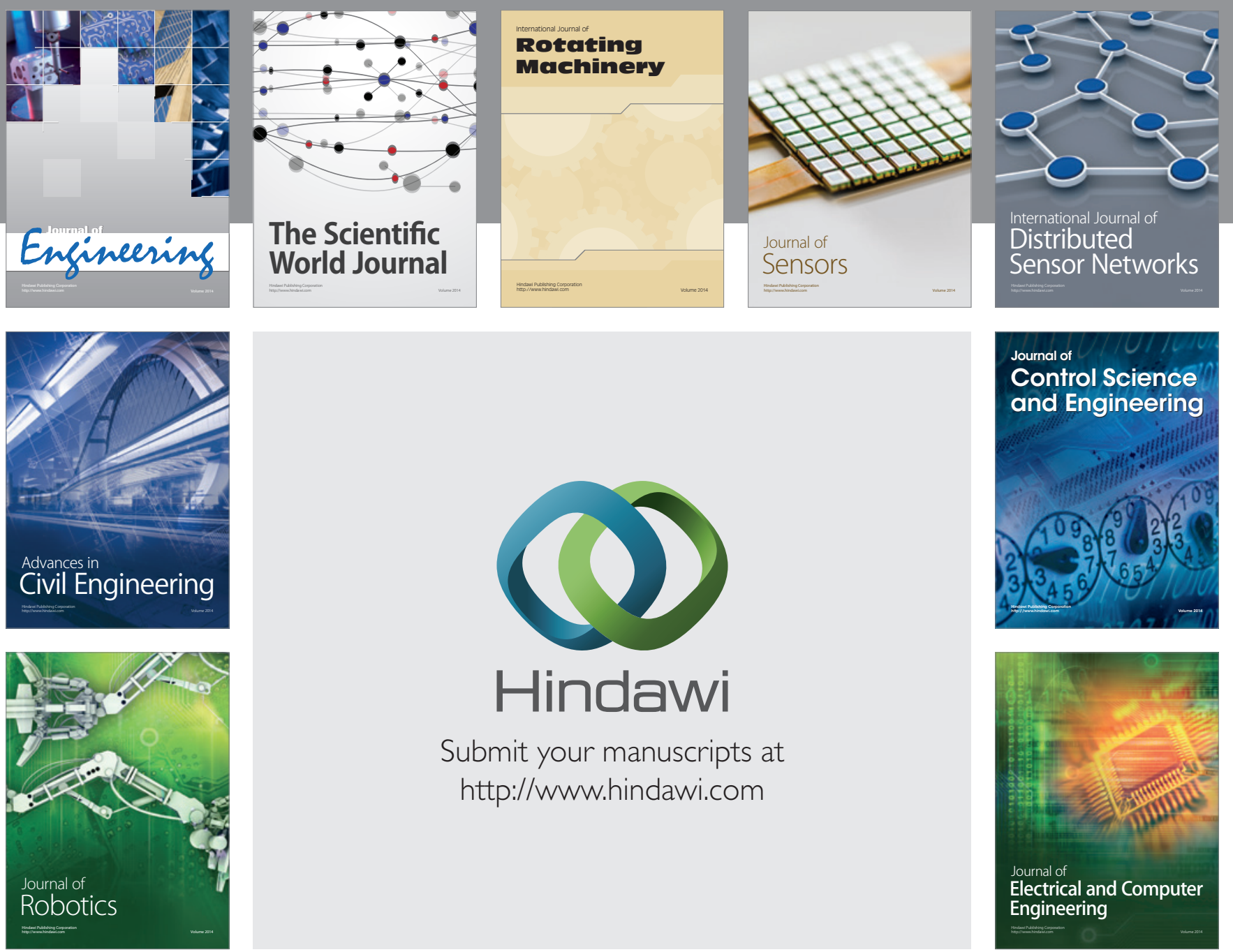

Submit your manuscripts at

http://www.hindawi.com
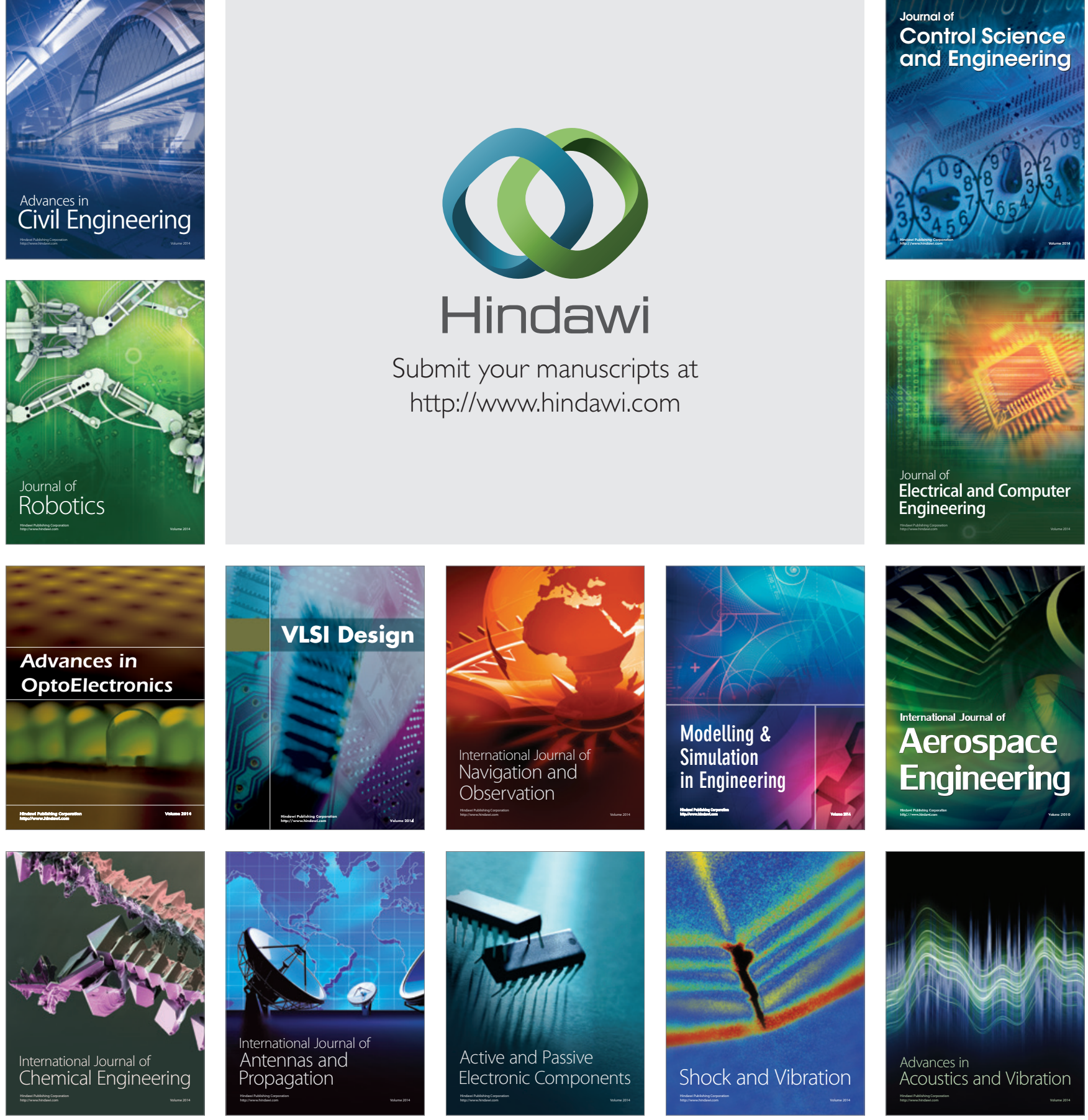